\title{
CHARACTERIZATIONS ON FRACTURE PROCESS ZONE OF PLAIN CONCRETE
}

\author{
Yuxiang TANG, Hongniao CHEN* \\ Space Structures Research Center, Guizhou University, Guiyang, China \\ Received 12 April 2019; accepted 16 May 2019
}

\begin{abstract}
The fracture property of concrete is essential for the safety and durability analysis of concrete structures. Investigating the characteristics of the fracture process zone (FPZ) is of great significance to clarify the nonlinear fracture behaviour of concrete. Experimental and numerical investigations on the FPZ of plain concrete in pre-notched beams subjected to three-point bending were carried out. Electronic speckle pattern interferometry (ESPI) technique was used to observe crack evolution and measure the full-field deformation of the beams. The development of the FPZ were evaluated qualitatively and quantitatively based on the in-plane strain contours and displacement field measured by ESPI, respectively. By integrating the cohesive crack model and finite element (FE) model, various tension softening curves (TSCs) were employed to simulate the fracture response of concrete beams. By comparing the deformation obtained by FE simulation and experiments, the TSCs of plain concrete were evaluated and most suitable TSCs of concrete were recommended.
\end{abstract}

Keywords: concrete, fracture process zone, tension softening, ESPI, cohesive crack model.

\section{Introduction}

Concrete material has been widely used in civil engineering and its fracture property is essential for the safety and durability evaluation of concrete structures. Considered as a heterogeneous and multiphase material, fracture failure of concrete is between brittleness and ductility, and the fracture process is very complicated. The fracture process zone (FPZ) is defined as the damage zone ahead of a real traction-free crack in quasi-brittle material (Bazant \& Cedolin, 1979; Hillerborg, Modéer, \& Petersson, 1976). It has been demonstrated that the fracture behavior of concrete exhibits a certain nonlinearity and the existing formula based on linear elastic fracture mechanics (LEFM) is invalid for concrete material due to the existence of the FPZ (Shah, Swartz, \& Ouyang, 1995). Furthermore, fracture energy is generally considered as a significant parameter in the fracture analysis of concrete structures (Kanomata et al., 2012) and affected by the height of the FPZ (Hu \& Duan, 2004), indicating that the presence of the FPZ may be the essential reason for the size effect of fracture energy $(\mathrm{Hu}, 2002)$. Therefore, it is of great significance to investigate the FPZ characteristics of concrete.

To monitor the development of micro cracks in quasibrittle materials, various measured techniques and means have been employed and can be divided into two catego- ries (Hadjab-Souag, Chabaat, \& Thimus, 2007a), the direct techniques and the indirect techniques, respectively. One is direct observation of material fracture and its use is ordinarily accompanied by destruction, such as X-rays technique (Yuan et al., 2015) and scanning electron microscope (Hadjab-Souag, Thimus, \& Chabaat, 2007b). The other is based on an attempt to observe the material indirectly and provides non-destructive real-time observation, such as optical surface-displacement measuring tool (Siebert, Schubach, \& Splitthof, 2011), acoustic emission technique (Arnautov et al., 2016) and Moiré interferometry (Guo, Kobayashi, \& Hawkins, 1993). Both electronic speckle pattern interferometry (ESPI) and digital image correlation (DIC) are powerful optical image measuring techniques to provide non-contact full-field displacement measurement. DIC technique can visualize the surface deformations of material by successive post-processing of digital images (Skarżyński, Syroka, \& Tejchman, 2011) and has been widely applied to study the fracture property of concrete structure, such as the FPZ length (Wu, Rong, Zheng, Xu, \& Dong, 2011), the FPZ width (Skarżyński \& Tejchman, 2010), the local deformation at the steel-concrete interface (Daoud, Maurel, \& Laborderie, 2013), deformation monitoring on the surface of reinforced concrete ties

${ }^{*}$ Corresponding author. E-mail: hqchen@gzu.edu.cn 
(Gribniak, Rimkus, Torres, \& Jakstaite, 2017), the crack propagation at rock-concrete interface (Dong, Wu, Zhou, Wang, \& Kastiukas, 2017). However, the measurement results of DIC depend largely on the quality of the imaging system, the selection of a particular correlation algorithm and the size of speckle, subset and filter (Bhowmik \& Ray, 2019; Pan, Qian, Xie, \& Asundi, 2009). Therefore, the accuracy of strain field measurement measured by DIC is lower than that ESPI results and researchers have used ESPI technique to study the fracture behaviors of various quasi-brittle materials, such as rock (Haggerty, Lin, \& Labuz, 2010), concrete (Chen \& Su, 2013; Tang \& Chen, 2018), mortar (Su, Chen, \& Kwan, 2012) and graphite (Su et al., 2013). In this study, ESPI technique was employed to measure full-field deformation of concrete.

The cohesive crack model (CCM) is usually used to analyze the fracture of concrete numerically due to its simplicity and physical meaning (Zhang, Yang, \& Gao, 2018). In the CCM, concrete softens progressively because of micro-cracking and other energy dissipation processes in the FPZ, such as aggregate bridging, crack branching and deflection. This can be expressed as the softening relationship between the residual stress transfer capacity $\sigma$ and the crack opening displacement $w$ in the FPZ, also known as the tension softening curve (TSC). As a significant fracture mechanics parameter, the TSC can be derived by two methods in general, direct method and indirect method, respectively. One is obtained by a direct uniaxial tensile test (Cornelissen, Hordijk, \& Reinhardt, 1986), while it is difficult to be performed due to some inevitable drawbacks: asymmetric modes of fracture, multiple cracking, and sudden failure of the specimen (Elices, Guinea, Gomez, \& Planas, 2002). The other is derived from an inverse analysis method by minimizing the difference between the numerical and experimental results (Sousa \& Gettu, 2006; Wittmann, Rokugo, Brühwiler, Mihashi, \& Simonin, 1988). Various shapes of the TSC has been developed to simulate the nonlinear fracture behavior of concrete as a constitutive law, such as linear, bilinear (Wittmann et al., 1988), tri-linear, and exponential (Chen \& Su, 2013; Reinhardt, Cornelissen, \& Hordijk, 1986).

In this study, the properties of the FPZ in concrete were investigated, containing both its geometric and softening characteristics. Three-point bending tests were conducted on pre-notched concrete beams and ESPI technology was used to obtain the full-field displacement during the entire process of crack propagation. In addition, based on the integration of the CCM and finite element (FE) model, various TSCs were employed to model the fracture behavior of concrete beams. By comparing the results obtained by numerical simulation and experiments, the TSCs of plain concrete were evaluated and most suitable TSCs of concrete were recommended.

\section{Cohesive crack model}

As a heterogeneous material, concrete exhibits highly complex cracking process, as well as different mechanical properties in different loading situations (Jakubovskis,
Kupliauskas, Rimkus, \& Gribniak, 2018). The CCM has been widely employed to simulate the nonlinear fracture behavior of a Mode I crack in quasi-brittle materials. As shown in Figure 1, the crack is divided into two parts in this model, real crack and cohesive crack, respectively. Due to the heterogeneity of concrete, local tensile strength of concrete may be different with the presence of structural imperfections. However, to simplify simulation process, the cohesive crack is assumed to develop when the stress at the crack tip approaches the tensile strength $f_{\mathrm{t}}$ in this study (Hillerborg et al., 1976). a)

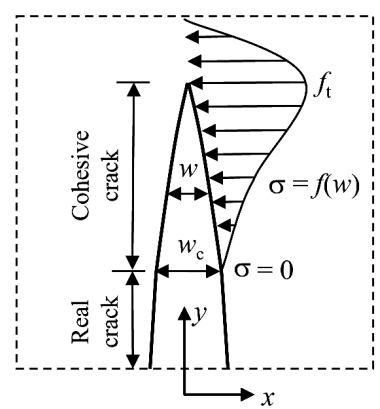

b)

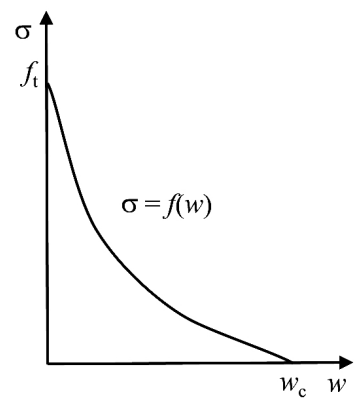

Figure 1. Cohesive crack model: (a) schematic of a cohesive crack, (b) cohesive constitute law

All the nonlinear behavior in fracture process is represented by a cohesive crack and the traction of the crack surfaces follows a cohesive constitute law, named as a TSC. The TSC, as shown in Figure 1(b), is typically represented as a stress-displacement relationship, which can be expressed as

$$
\sigma=f(w), 0 \leq w \leq w_{c},
$$

where $\sigma$ is the cohesive stress, $w$ is the crack opening displacement in the cohesive zone, also known as the FPZ, and $w_{c}$ is the characteristic crack opening displacement at which $\sigma$ reaches zero.

The TSC is often approximated as a linear, bilinear, trilinear or exponential curve for numerical analysis. Among the various softening curves, the bilinear and exponential softening relationships have been utilized extensively (Cendón, Gálvez, Elices, \& Planas, 2000) and are adopted in this study. The softening relationship is generally dominated by the tensile strength $f_{\mathrm{t}}$ and the fracture energy $G_{\mathrm{F}}$.

\section{Experimental technique and setup}

\subsection{ESPI technique}

The principle of ESPI measurement is based on the interference of two coherent laser beams, an object beam and a reference beam respectively, as shown in Figure 2. In the measurement, the laser from the laser diode is divided into two beams by the beam splitter. The two beams are reflected and scattered by the rough measured surface. The reflected beams are overlaid to produce a speckle pattern, which is captured and recorded by a charge coupled 


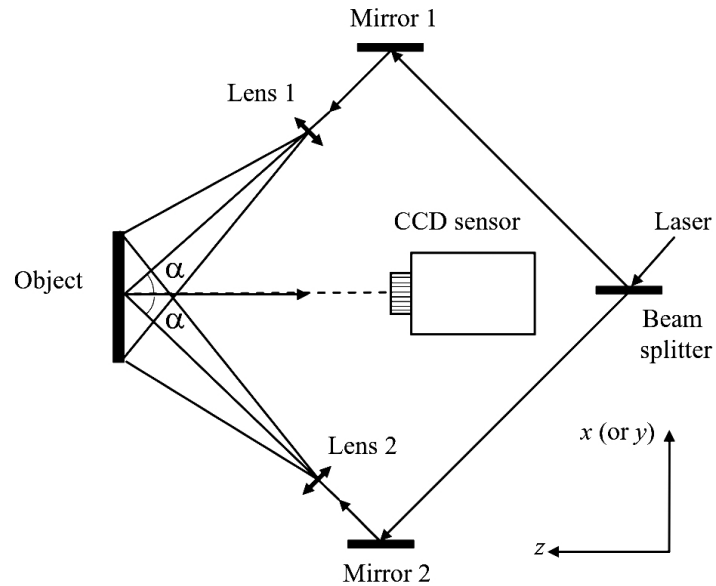

Figure 2. Schematic of ESPI setup for measurement

device (CCD) sensor. By subtracting the speckle patterns at two stages (before deformation and after deformation), regular interference fringes with dark and bright areas can be obtained. The phase difference between the two states, also known as wrapped phase map, can be calculated by using the four-step phase shifting method (Huntley \& Saldner, 1993). After phase unwrapping, displacement contour map of the measuring area can be obtained. The entire ESPI measurement procedure is shown in Figure 3 and more details on the principle of ESPI can be found in Chen, Su, Fok, and Zhang (2017).

\subsection{Specimens and experimental setup}

Two groups of concrete specimens with different compressive strengths were cast, including normal strength concrete (NSC, $40 \mathrm{MPa}$ ) and high strength concrete (HSC, $90 \mathrm{MPa}$ ). Portland Cement I 52.5N (British Standards Institution [BSI], 2007) was used. The coarse aggregate was crushed granite with the maximum diameter of $10 \mathrm{~mm}$ and the fine aggregate was river sand. The mix propor- tions of concrete are listed in Table 1. There are three prenotched beams of each strength concrete were prepared for conducting three-point bending tests. The dimensions (length $\times$ depth $\times$ thickness) of the beams were $710 \times 150 \times 80$ $\mathrm{mm}^{3}$ and the span was $600 \mathrm{~mm}$. The depth and thickness of the pre-notch were $45 \mathrm{~mm}$ and $3 \mathrm{~mm}$, respectively.

Besides the pre-notched beams, three cubes $\left(150 \times 150 \times 150 \mathrm{~mm}^{3}\right)$ were cast with each batch and tested to determine the compressive strength $f_{\mathrm{cu}}$ of concrete after cured for 28 days in air (temperature: $20 \pm 2{ }^{\circ} \mathrm{C}$; relative humidity: $75-85 \%)$. To eliminate the variation of material properties of different specimens, cylinders were cored from the pre-notched beams after performing the threepoint bend tests. The dimensions (diameter $\times$ depth) of the cylinders were $100 \mathrm{~mm} \times 80 \mathrm{~mm}$. To measure the tensile strength $f_{\mathrm{t}}$, the splitting tension test were conducted on the cylinder specimens. The material properties of concrete are shown in Table 1.

Three-point bending tests were carried out using an MTS bend fixture. The experimental setup is presented in Figure 4. An actuator was moved upward to apply load on the beam using displacement control with a loading rate of $0.01 \mathrm{~mm} / \mathrm{min}$. The main crack growth was well controlled by using a closed-loop servo hydraulic control system. The crack mouth opening displacement (CMOD) and mid-span deflection $\delta$ were measured by a clip gauge and LVDTs respectively and recorded by a data logger. To reduce the influence of supports on deflection measurement, as shown in Figure 4(b), an additional frame was placed at the top of the specimen as a reference datum for LVDTs.

To measure the surface deformation at the mid-span of the beams, a three-dimensional ESPI system (Q300 produced by Dantec-Ettemeyer) was employed and the technical specifications of Q300 system are tabulated in Table 2 . The measuring area was about $200 \mathrm{~mm}(\mathrm{H}) \times 170 \mathrm{~mm}(\mathrm{~V})$ in this study. With the present setup, the measurement

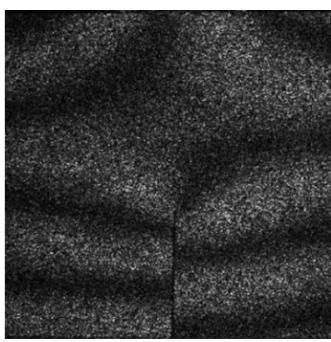

Interference fringes

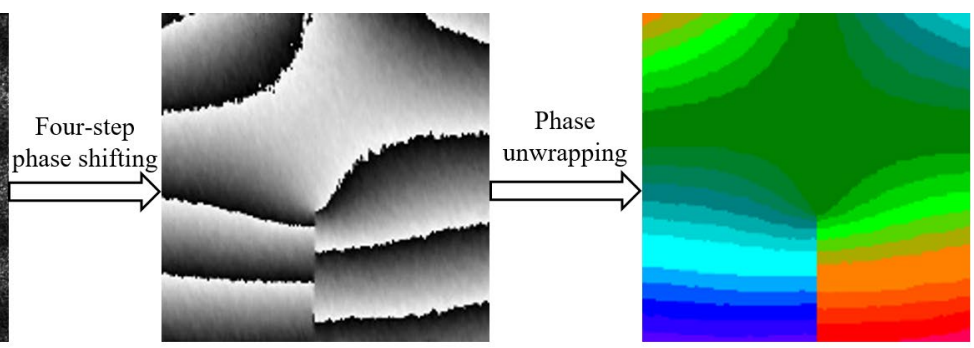

Wrapping phase map

Displacement contour map

Figure 3. The entire ESPI measurement procedure

Table 1. Mix proportions and material properties of concrete

\begin{tabular}{|c|c|c|c|c|c|c|c|}
\hline Groups & $\begin{array}{c}\text { Fine aggregate } \\
\left(\mathrm{kg} / \mathrm{m}^{3}\right)\end{array}$ & $\begin{array}{c}\text { Coarse aggregate } \\
\left(\mathrm{kg} / \mathrm{m}^{3}\right)\end{array}$ & $\begin{array}{c}\text { Water } \\
\left(\mathrm{kg} / \mathrm{m}^{3}\right)\end{array}$ & $\begin{array}{c}\text { Cement } \\
\left(\mathrm{kg} / \mathrm{m}^{3}\right)\end{array}$ & $\begin{array}{c}\text { Super plasticizer } \\
\left(\mathrm{g} / \mathrm{m}^{3}\right)\end{array}$ & $\begin{array}{c}f_{\mathrm{cu}} \\
(\mathrm{MPa})\end{array}$ & $\begin{array}{c}f_{\mathrm{t}} \\
(\mathrm{MPa})\end{array}$ \\
\hline NSC & 1025 & 838 & 200 & 279 & 0 & 39.7 & 2.5 \\
\hline HSC & 867 & 866 & 160 & 501 & 8516 & 86.7 & 5.4 \\
\hline
\end{tabular}


a)

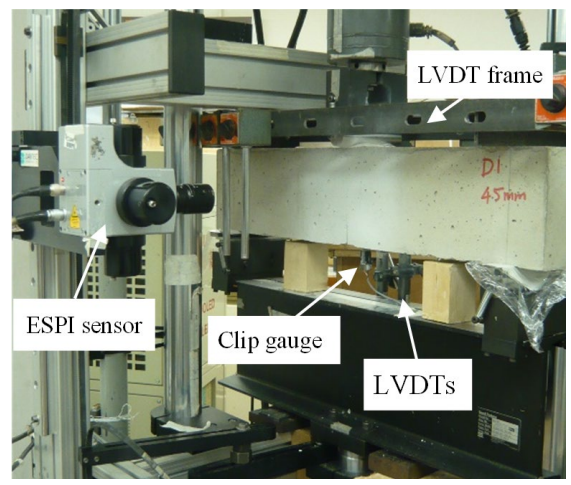

b)

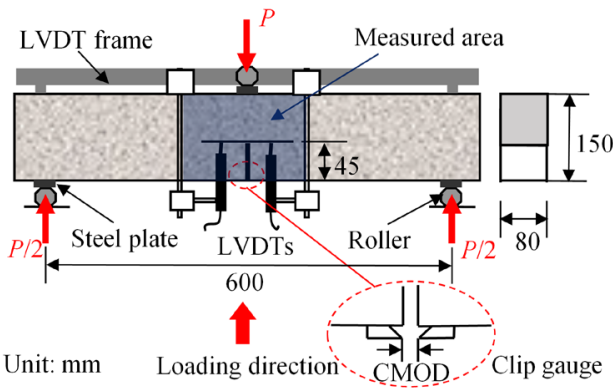

Figure 4. Three-point bending test: (a) experimental photo, (b) sketch of test setup

Table 2. Technical specifications of ESPI system

\begin{tabular}{|l|l|}
\hline \multicolumn{1}{|c|}{ Parameters } & \multicolumn{1}{c|}{ Technical specifications } \\
\hline Displacement accuracy & Adjustable, $0.05-1 \mu \mathrm{m}$ \\
\hline CCD-resolution & 1392 (horizontal) $\times 1040$ (vertical) pixels \\
\hline Measured range & Adjustable, $10-100 \mu \mathrm{m}$ per step depending on measuring direction \\
\hline Measuring area & $200 \mathrm{~mm}($ horizontal) $\times 170 \mathrm{~mm}$ (vertical) in this study \\
\hline Camera position & $350-355 \mathrm{~mm}$ \\
\hline Laser (built in) & Diode, $2 \times 75 \mathrm{~mW}, \lambda=785 \mathrm{~nm}$ \\
\hline
\end{tabular}

accuracy of ESPI is approximately $0.2 \mu \mathrm{m}$. At each record step, the speckle pattern on the measuring area was captured by an ESPI sensor. A post-processing software, ISTRA (Dantec-Ettemeyer, 2001), was applied to convert the raw data into full-field displacement distributions.

\section{Experimental results}

\subsection{Load-displacement curves and fracture parameters}

From the data logger readings, the complete load $P$ versus deflection $\delta$ and $P$ versus CMOD curves of the specimens were obtained and presented in Figure 5(a) and Figure 5(b), respectively. It can be seen that, the load- displacement curves of concrete specimens with the same strength might be different because of the diversity of individual samples and the heterogeneity of concrete. The CMOD can also be determined from the crack opening displacement curve measured by ESPI (as illustrated in Section 3.3). Taking sample NSC-1 as an example, the CMOD obtained by a clip gauge and ESPI are compared and shown in Figure 5(c). It can be seen that ESPI results show excellent agreement with the results obtained by a clip gauge, which validates the accuracy of ESPI measurement.

According to RILEM's recommendations (RILEM, $1985,1990)$, the fracture energy $G_{F}$ and the young's modulus $E$ of concrete can be determined by the entire $P-\delta$ curve and the measured initial compliance $C_{i}$ of $P$-CMOD curve, respectively, which are expressed as

$$
G_{F}=\frac{A_{0}}{\left(D-a_{0}\right) t}
$$

in which $A_{0}$ is the area under the load-deflection curve, $D$ and $t$ are the depth and the thickness of the beam, respectively, and $a_{0}$ is the depth of the initial notch.

$$
E=\frac{6 S a_{0} V_{1}\left(\alpha_{0}\right)}{C_{i} D^{2} t}
$$

for span-depth ratio $S / D=4$, the function $V_{1}\left(\alpha_{0}\right)$ can be expressed as

$V_{1}\left(\alpha_{0}\right)=0.76-2.28 \alpha_{0}+3.87 \alpha_{0}^{3}-2.04 \alpha_{0}^{3}+0.66 /\left(1-\alpha_{0}\right)^{2}$,

where $\alpha_{0}=a_{0} / D$.

The fracture parameters of each specimens are listed in Table 3. From the table, it can be found that the mean value of the fracture energy of NSC $(98.4 \mathrm{~N} / \mathrm{m})$ is smaller than that of HSC $(114.8 \mathrm{~N} / \mathrm{m})$. This may due to the fact that crack mainly develops along the weaker aggregate-matrix transition zone in NSC. While for HSC, crack propagates through the aggregates (Chen \& Su, 2013) causing crack extension per unit area dissipates more energy.

\subsection{Evolution of the FPZ}

To investigate the evolution of the FPZ, it is necessary to define the FPZ region. Displacement and strain distributions in $x$ direction (denoted as $u$ and $\varepsilon_{\mathrm{xx}}$, respectively) at the same height of crack are presented in Figure 6. It can be seen that there are two displacement jumps occur near the central position. Similar phenomenon was found by $\mathrm{Wu}$ et al. (2011), who indicated that the displacement jump was caused by the formation of micro cracks. The bifurcations of the crack can also be observed from the 
a)

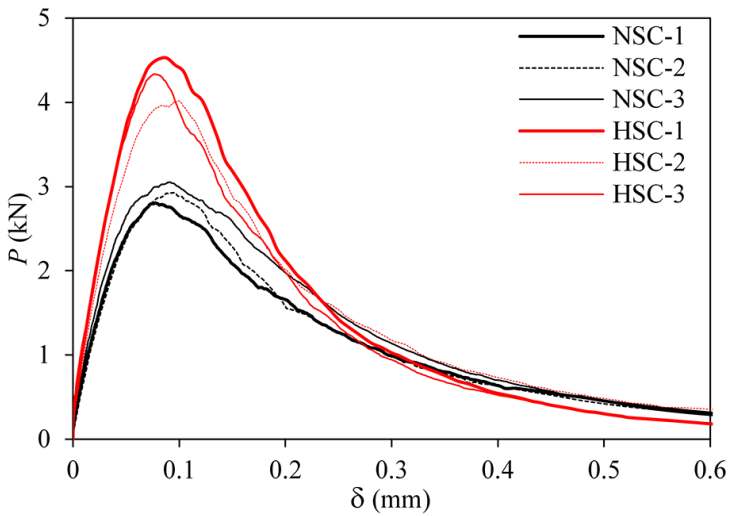

b)

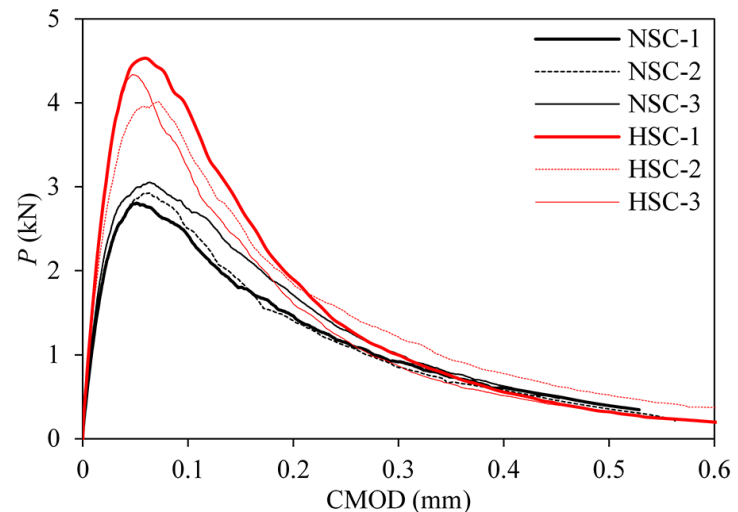

c)

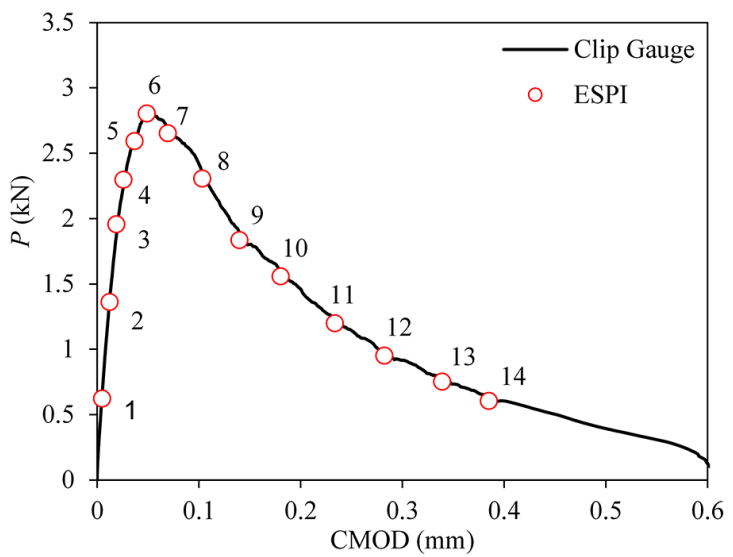

Figure 5. Load-displacement curves: (a) $P$ versus $\delta$ of all specimens, (b) $P$ versus CMOD of all specimens,;

(c) $P$ versus CMOD of Specimen NSC-1

Table 3. Experiment results of concrete specimens

\begin{tabular}{|l|c|c|c|c|c|c|}
\hline \multicolumn{1}{|c|}{ Sample No. } & $P_{\max }(\mathrm{kN})$ & $\delta_{\mathrm{c}}(\mathrm{mm})$ & $\mathrm{CMOD}_{\mathrm{c}}(\mathrm{mm})$ & $\mathrm{CTOD}_{\mathrm{c}}(\mathrm{mm})$ & $G_{\mathrm{F}}(\mathrm{N} / \mathrm{m})$ & $E(\mathrm{GPa})$ \\
\hline NSC-1 & 2.805 & 0.077 & 0.051 & 0.025 & 95 & 21 \\
\hline NSC-2 & 2.920 & 0.088 & 0.058 & 0.026 & 95.8 & 21.2 \\
\hline NSC-3 & 3.048 & 0.089 & 0.062 & 0.025 & 104.5 & 21.5 \\
\hline Mean value & 2.924 & 0.085 & 0.057 & 0.025 & 98.4 & 21.3 \\
\hline Std dev. & 0.122 & 0.007 & 0.006 & 0.001 & 5.269 & 0.252 \\
\hline HSC-1 & 4.524 & 0.088 & 0.062 & 0.031 & 115.4 & 31 \\
\hline HSC-2 & 4.016 & 0.110 & 0.072 & 0.031 & 121.1 & 30.2 \\
\hline HSC-3 & 4.230 & 0.088 & 0.058 & 0.026 & 108 & 29.8 \\
\hline Mean value & 4.257 & 0.095 & 0.064 & 0.029 & 114.8 & 30.3 \\
\hline Std dev. & 0.255 & 0.013 & 0.007 & 0.003 & 6.568 & 0.611 \\
\hline
\end{tabular}

Notes: $P_{\max }, \delta_{\mathfrak{c}}, \mathrm{CMOD}_{\mathrm{c}}$ and $\mathrm{CTOD}_{\mathrm{c}}$ are the load, deflection, $\mathrm{CMOD}$ and CTOD at the peak, respectively.

two displacement jumps. Away from the jump, the displacement distribution is nearly horizontal, indicating that this part of concrete is still in an elastic state. The width of FPZ is the thickness of the damage zone containing all the cracks (Chen \& Su, 2013). Therefore, the start and end points of the displacement jumps can be considered as the left and right boundary points of the FPZ, denoted as $L$ and $R$, respectively. It can be found that the strain at the left and right borders of the FPZ are almost identical and approximately equal to $0.25 \times 10^{-3}$, which can be considered as the maximum tensile strain of concrete.
In this study, the FPZ extent was defined as the location where the strain $\varepsilon_{\mathrm{xx}}$ reached $0.25 \times 10^{-3}$ and the development of the FPZ were observed based on the in-plane strain contours of four typical loading stages (see Figure $5)$ and presented in Figure 7.

As shown in Figure 7, at the pre-peak $49 \%$ of the peak load $\left(P_{2}\right)$, the main crack initiates from the initial notch tip and the material has some damage caused by the micro cracks. At the peak load $\left(P_{6}\right)$, the main crack deviates from the original path and propagates along the aggregate. It can be observed that the previous microcracks on the 


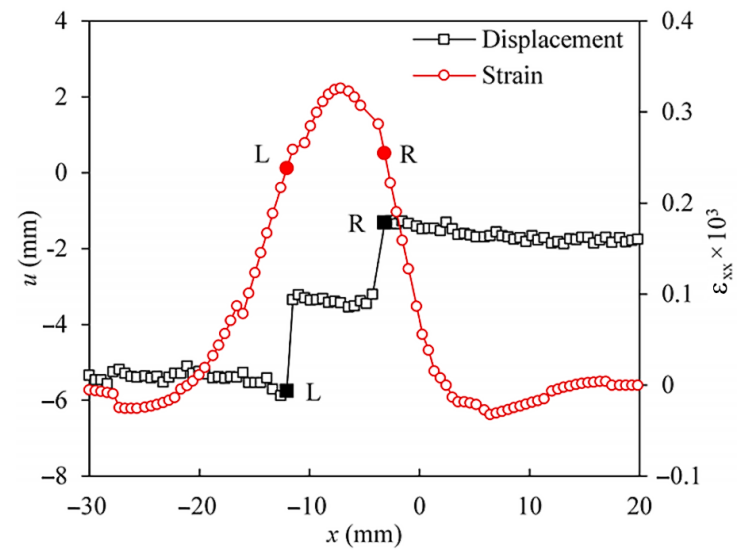

Figure 6. Displacement and strain distributions in $x$ direction at the same height of crack

left (see Figure 7a) aggregate with the main crack. The dimensions (length $\times$ width) of the FPZ are approximately $35 \mathrm{~mm} \times 17 \mathrm{~mm}$ at this stage. After the peak load, the crack propagates extensively and there may be an aggregate with a diameter of $5 \mathrm{~mm}$ at $y=80 \mathrm{~mm}$. Thus, the crack bifurcates to circumvent this aggregate, which can be seen from Figure $7 \mathrm{c}$. Micro cracks closure occurs near the precast notch tip and the FPZ is about $65 \mathrm{~mm} \times 27 \mathrm{~mm}$ when the load reduced to $82 \% P_{\max }\left(P_{8}\right)$. When the FPZ is fully developed ( $P_{12}$, post-peak $34 \%$ of $P_{\max }$, which is illustrated in the Section 3.3), micro cracks have been fully developed and form an irregular narrow and long band through the whole cross section. It could be noted that, compared with the previous loading stage, the length of the FPZ has been reached the maximum about $92 \mathrm{~mm}$ while the width of it has been narrowed by about $21 \mathrm{~mm}$, which indicates that some micro cracks have been partially closed with the expansion of the main crack. The maximum width of the FPZ is about 2.7 times the maximum aggregate size in this specimen. The experimental observation in this study is consistent with previous findings that the FPZ width is approximately three times the maximum aggregate size
(Denarie, Saouma, Iocco, \& Varelas, 2001). As similar results can be observed for HSC, the strain contours of HSC are not presented here due to the limited space.

It could be concluded from the observed initiation and evolution of the FPZ that, the FPZ is mainly formed by the localization and extension of the micro cracks and develops slowly in the pre-peak stage, while after the peak load, the FPZ expands rapidly and is mostly attributed to the bridging effect between the aggregates and cement matrix. Due to the random distribution of the aggregate in concrete, micro cracking, crack branching and crack deflection occur along the growth path of the main crack. The main crack always propagates towards the stress concentration at the loading point in spite of that and the fully developed FPZ presents an irregular narrow and long band.

\subsection{Variation of the FPZ length}

The length of the FPZ is an essential parameter to characterize the fracture behavior of concrete and predict the failure of concrete members (Li \& Marasteanu, 2010). It should be pointed out that the evolution of FPZ can only be qualitatively evaluated based on the strain field. Since the discontinuity of crack region can cause deviations when the strain is calculated by a reference length (Wu et al., 2011). To quantitatively analyze the variation of the FPZ length, the displacement field measured by ESPI is utilized and the crack opening displacement profile needs to be obtained first.

The crack opening displacement $w$ can be determined by subtracting displacements in $x$ direction at both sides of the crack path (Hamad, Owen, \& Hussein, 2013; Su et al., 2012). Figure 8 shows the crack opening $w$ along the height $y$ of Specimen NSC-1 at different loading levels. The crack front $y_{\mathrm{t}}$ can be defined as the position where the $w$ reduces to zero and the tip of the initial notch $\left(y_{0}=45\right.$ $\mathrm{mm}$ ) is considered as the end of the cohesive crack when the FPZ has not been fully developed. The length of FPZ, $l_{\mathrm{FPZ}}$, can be calculated by subtracting $y_{0}$ from $y_{\mathrm{t}}$. a)

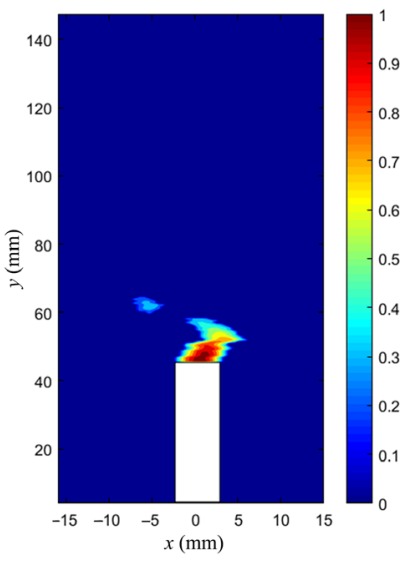

b)

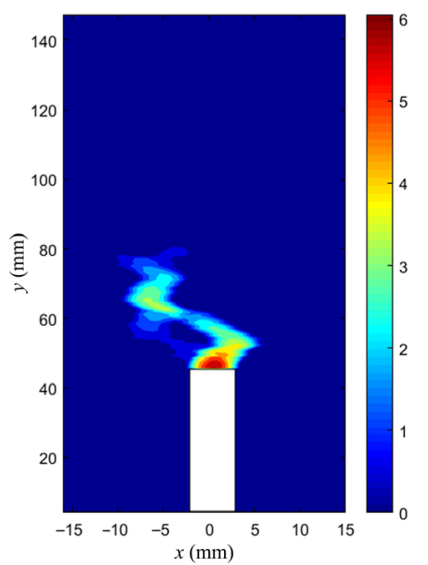

c)

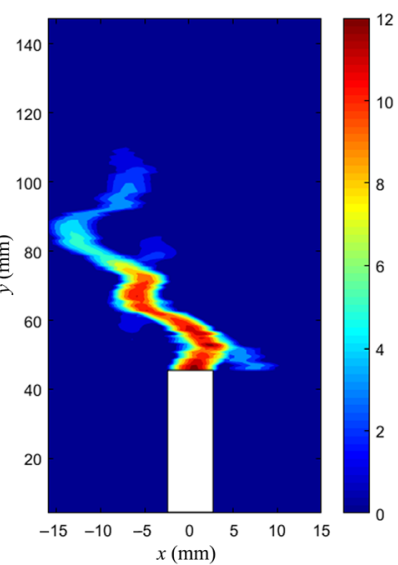

d)

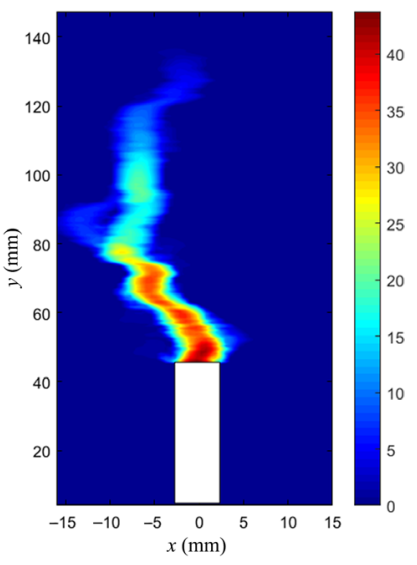

Figure 7. Strain contours in the $x$ direction of NSC-1 at four typical loading levels: (a) $P_{2}$ (pre-peak, $49 \% P_{\max }$ ),

(b) $P_{6}$ (peak load, $P_{\max }$ ), (c) $P_{8}$ (post-peak, $82 \% P_{\max }$ ), (d) $P_{12}$ (post-peak, $34 \% P_{\max }$ ) (unit: $1 \times 10^{-3}$ ) 
As presented in Figure 8(a), at loading point $P_{8}$ (postpeak $82 \%$ of the peak load), the $l_{\mathrm{FPZ}}$ is approximately 66.97 $\mathrm{mm}, 0.64$ times the ligament length $\left(D-a_{0}\right)$. The crack opening displacements at the tip $(y=45 \mathrm{~mm})$ and mouth $(y=0 \mathrm{~mm})$ of the precast notch (see Figure 8(b)), which are named CTOD and CMOD, are about $62.1 \mu \mathrm{m}$ and $103 \mu \mathrm{m}$, respectively. As shown in Figure 8(b), when the FPZ is fully developed, the rear end of the cohesive crack moves forward $\Delta a$. Therefore, it's indispensable to determine the new end of the crack to estimate the FPZ length.

According to the CCM, the cohesive stress $\sigma$ in the FPZ can be expressed as a function of the crack opening $w$. The $w$ corresponding to the fully-developed FPZ is the characteristic crack opening displacement $w_{c}$ when $\sigma$ is equal to 0 . Wittmann et al. (1988) suggest that $w_{\mathrm{c}}$ equal to $5 G_{\mathrm{F}} / f_{\mathrm{t}}$. For sample NSC-1, the measured values of $G_{\mathrm{F}}$ and $f_{\mathrm{t}}$ are $92 \mathrm{~N} / \mathrm{mm}$ and $2.5 \mathrm{MPa}$, respectively. Correspondingly, the $w_{c}$ is equal to $190 \mu \mathrm{m}$. When the load reduces to $\mathrm{P}_{12}$ (post-peak $34 \%$ of the peak load), the CTOD is about equal to $w_{\mathrm{c}}$. Consequently, the FPZ is just fully developed and its length reaches the maximum value, which is approximately $95.96 \mu \mathrm{m}$ and 0.91 times the ligament. At the loading level of post-peak $27 \% P_{\max }\left(P_{13}\right)$, the CTOD is about $227.6 \mu \mathrm{m}$ and larger than $w_{\mathrm{c}}$. Therefore, the rear end of the FPZ moves about $16.23 \mathrm{~mm}$ forward and the FPZ length is approximately $80.64 \mathrm{~mm}$, equal to 0.77 times the ligament length.

To further evaluate the evolution of the length of the FPZ for different strength concrete, the normalized load $P / P_{\max }$ and $\left(a-a_{0}\right) /\left(D-a_{0}\right)$ were used. $P / P_{\max }$ versus $l_{\mathrm{FPZ}}$ curves and $l_{\mathrm{FPZ}}$ versus $\left(a-a_{0}\right) /\left(D-a_{0}\right)$ curves during the whole fracture process are presented in Figure 9. As shown in the figure, the FPZ evolution in various strength exhibit similar behaviors. When the load is less than $0.33 P_{\max }$, the concrete material is in an elastic deformation stage and fracture toughening is relatively slight. After that, micro cracks and bifurcations form and the FPZ develop rapidly. At the peak loading level, $l_{\mathrm{FPZ}}$ is about $37 \mathrm{~mm}$ and the crack extends 0.35 times ligament length. When the load reduces to approximately 0.33 of the peak load, the FPZ is just fully developed and its length reaches a maximum, which is about $90 \mathrm{~mm}$. At this moment, the crack propagates approximately 0.86 times the length of the ligament. Similar phenomenon was observed by $\mathrm{Wu}$ et al. (2011), who reported that the FPZ is fully developed at a crack extension length to ligament length ratio of about 0.91 by DIC measurement. With the further extension of the crack, the length of the FPZ decreases almost linearly. a)

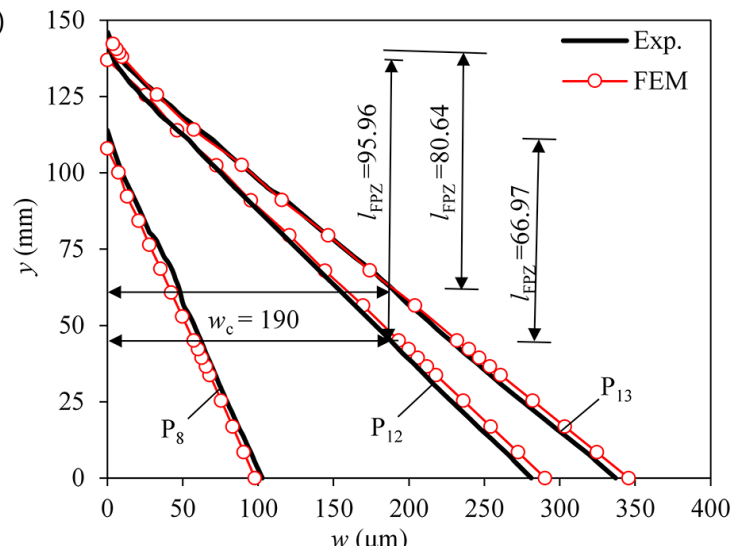

b)

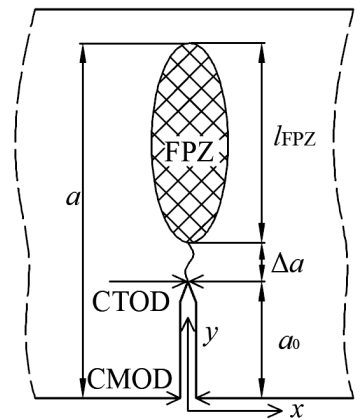

Figure 8. The length of FPZ: (a) the crack opening displacement curves of specimen NSC-1, (b) schematic diagram

a)

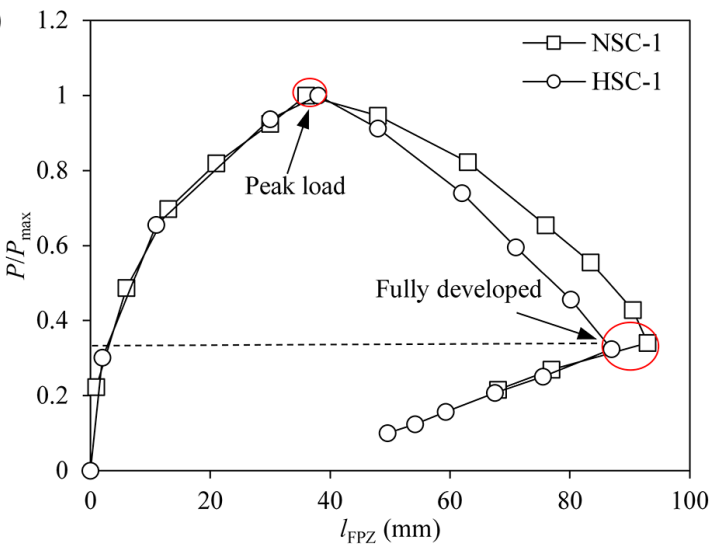

b)

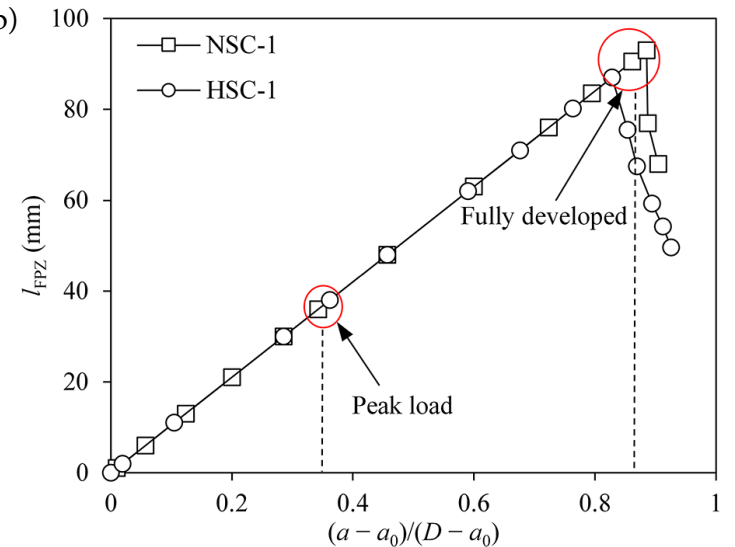

Figure 9. Variation of the FPZ length for different strength concrete: (a) $P / P_{\max }$ versus $l_{\mathrm{FPZ}}$ curves, (b) $l_{\mathrm{FPZ}}$ versus $\left(a-a_{0}\right) /\left(D-a_{0}\right)$ curves 
This phenomenon is probably because the crack tip is too close to the beam boundary and the residual ligament length is so short that the development of the FPZ is confined, causing the crack opening is more apparent than the propagation of the crack.

\section{Numerical simulation}

\subsection{Numerical model}

Using a finite element method (FEM) program written in FORTRAN, the three point bend test was simulated. Due to the symmetry of the beam, only one-half of the beam was analyzed and it was assumed that a crack propagated in the middle section of the beam along a straight line. A two-dimensional FE model and its meshes were shown in Figure 10. The 2-D beam was discretized using a total of 450 nine-node hybrid elements (Sze, Fan, \& Chow, 1995) in this study. The bulk material was assumed to be linear elastic. The young's modulus $E$ and the tensile strength $f_{\mathrm{t}}$ took the values listed in Table 3 and Table 1, respectively. The Poisson's ratio of concrete was assumed to be 0.2 in this analysis.

Taking specimen NSC-1 at $P_{8}$ loading point as an example, according to the concept of CCM and the experimental COD profiles, the numerical model in the $y$ direction was divided into three zones: the real crack

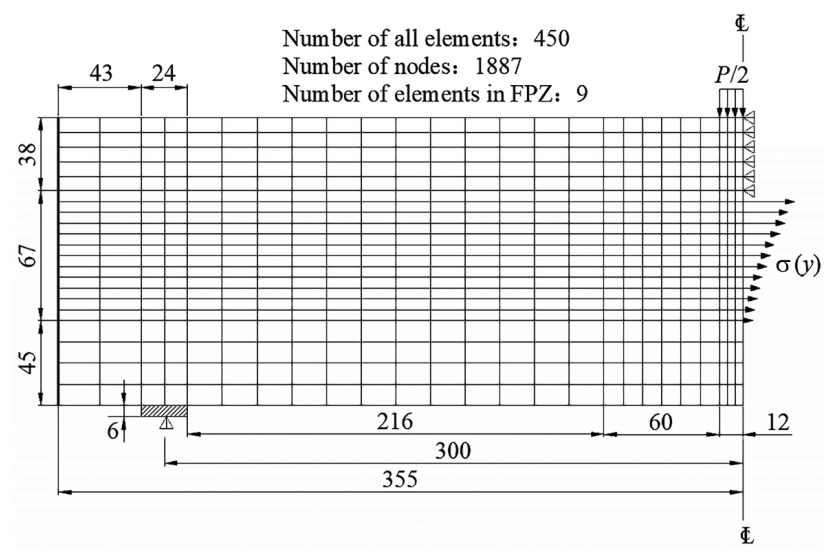

Figure 10. Finite element model and meshes (unit: $\mathrm{mm}$ )

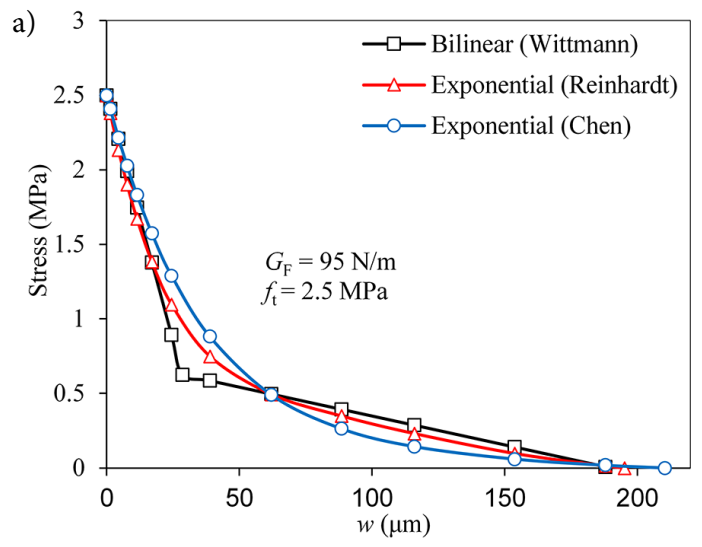

zone corresponding to the initial notch $(y=0-45 \mathrm{~mm})$, cohesive crack zone defined as the length of the FPZ ( $y=$ $45-112 \mathrm{~mm})$ and linear elastic zone where $w=0(y=$ $112-150 \mathrm{~mm}$ ). In the cohesive crack zone, the cohesive stress was calculated by the pre-supposed TSC based on the experimental COD profiles and added onto the nodes in the cohesive zone. In the linear elastic zone, only vertical displacement was allowed by applying constraints on the nodes.

To explore the influence of the softening function on the numerical results, three representative softening functions were used in this paper: the bilinear function proposed by Wittmann et al. (1988), which was determined by means of the compact tension test, the exponential function derived directly by Reinhardt et al. (Cornelissen, et al., 1986; Reinhardt et al., 1986), who performed a large amount of uniaxial tension tests, and the exponential function proposed by Chen and $\mathrm{Su}$ (2013), which is obtained by an inverse analysis method in a step by step manner and related to the compressive strength $f_{\text {cu }}$.

Based on the measured crack opening $w$, the three TSCs for specimens with different compressive strength are presented in Figure 11. It can be seen that, for normal strength concrete, the two exponential curves obtained by direct and indirect methods are similar with each other, which demonstrates the feasibility of inverse analysis to obtain the TSC. For high strength concrete, the initial segments of the two exponential TSCs are consistent with each other, while the tail of the TSC determined indirectly by Chen et al. (2017) is much longer than the TSC obtained directly by Reinhardt et al. (1986). It is worth noting that the compressive strength of concrete specimens used by Reinhardt et al. (1986) was 48.6 MPa and close to the strength of NSC used in this study.

\subsection{Numerical results}

By applying the calculated cohesive stress to the cohesive zone, the nonlinear fracture response of the beam was simulated. Comparisons between numerical and experimental results including load $P$ versus deflection $\delta$ curves, $P$-CMOD curves and $P$ versus CTOD curves for two types of concrete beams are shown in Figure 12. The numerical

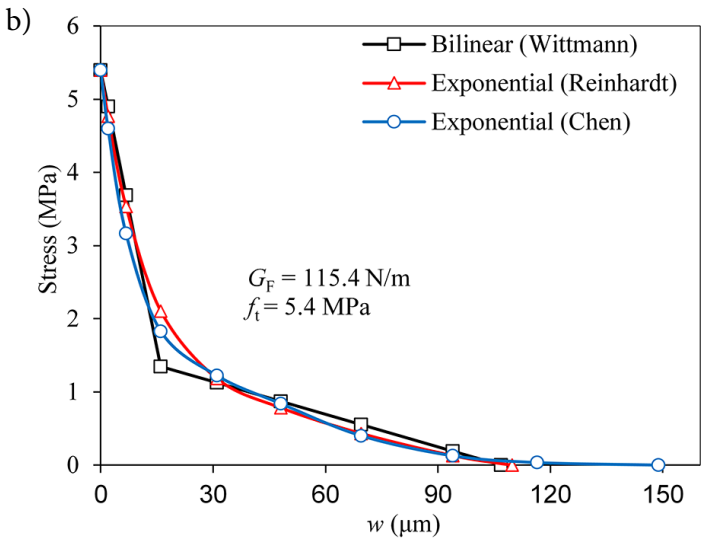

Figure 11. Tension softening curves for concrete specimens with different compressive strength: (a) NSC-1, (b) HSC-1 

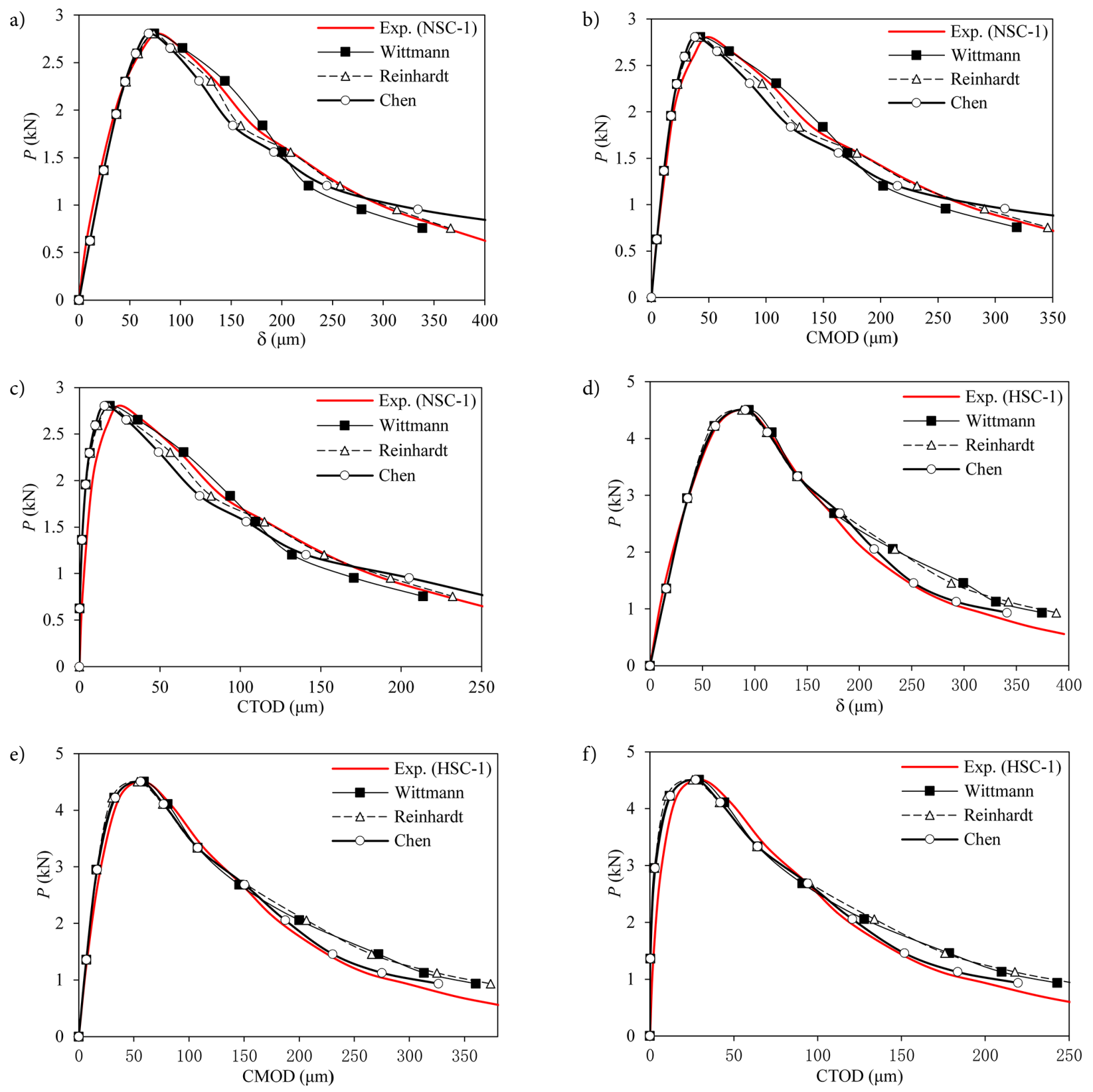

Figure 12. Experimental and numerical load-displacement curves for two types of concrete specimens. NSC-1: (a) $P$ versus $\delta$ curves, (b) $P$ versus CMOD curves, (c) $P$ versus CTOD curves; HSC-1: (d) $P$ versus $\delta$ curves, (e) $P$ versus CMOD curves, (f) $P$ versus CTOD curves

load-displacement curves agree well with the experimental load-displacement curves, which verifying the validity and accuracy of the FE model.

As shown in Figures 12(a)-12(c), for normal strength concrete, the numerical model using the bilinear and exponential softening relationship has a good prediction of the experimental results before the peak load level. However, in the post-peak loading stage, the simulation results obtained by the exponential softening model are more consistent with the test results than the bilinear softening model. To quantitatively compare the prediction effect of various TSCs, the root-mean-square error (RMSE) was evaluated, as tabulated in Table 4. By comparison, it can be found that the Reinhardt's (Reinhardt et al., 1986) sof- tening function provides preferable numerical predictions during the whole fracture process as the RMSE of that is minimal, indicating that the direct method to determine the tension softening curves is the most accurate despite its difficulty to implement. In this analysis, the exponential softening function determined by direct tensile tests gives the best approximation of the numerical results for normal strength concrete.

It can be found from Figures 12(d)-12(f) that, similar with NSC, both the bilinear and two exponential softening functions can give a satisfactory simulation of the test results in the pre-peak stage for HSC. The reason for this may be that the FPZ develops relatively slowly before the peak load as shown in Figure 7, indicating that the sof- 
Table 4. RMSE of experimental and numerical results

\begin{tabular}{|l|c|c|c|c|c|c|}
\hline \multirow{2}{*}{\multicolumn{1}{c|}{ TSCs }} & \multicolumn{3}{|c|}{ NSC-1 } & \multicolumn{3}{c|}{ HSC-1 } \\
\cline { 2 - 7 } & $\delta(\mu \mathrm{m})$ & CMOD $(\mu \mathrm{m})$ & CTOD $(\mu \mathrm{m})$ & $\delta(\mu \mathrm{m})$ & CMOD $(\mu \mathrm{m})$ & CTOD $(\mu \mathrm{m})$ \\
\hline Wittmann et al. (1988) & 14.829 & 13.674 & 9.477 & 13.063 & 12.039 & 9.547 \\
\hline Reinhardt et al. (1986) & 5.111 & 5.891 & 4.859 & 13.093 & 12.110 & 9.622 \\
\hline Chen and Su (2011) & 30.455 & 31.277 & 12.188 & 9.101 & 10.597 & 7.518 \\
\hline
\end{tabular}

tening characteristic of the FPZ has little influence on the fracture response of concrete beams in this stage. After the peak load, especially when the CTOD is greater than $100 \mu \mathrm{m}$, the exponential softening relationship proposed by Chen and $\mathrm{Su}$ (2011), which is relevant to the compressive strength, has a preferable numerical prediction of the experimental curves. Analyzing the reason, as shown in Figure $11 \mathrm{~b}$, the cohesive stress determined by the TSC proposed by Chen and $\mathrm{Su}$ (2011) is higher than the stress calculated from the other TSCs when the crack opening is greater than $100 \mu \mathrm{m}$. With higher cohesive stress, the force that prevents the propagation of cracks is greater, causing lower displacements in the numerical calculation. Thus, it is necessary for estimating the softening relationship of concrete material to consider concrete strength.

Considering the local responses of pre-notched beam, the COD profiles of NSC-1 at various loading level, which are obtained by numerical simulation using the exponential softening model (proposed by Reinhardt et al. (1986)) and the ESPI measurement, are compared and represented in Figure 8(a). An excellent agreement between the numerical and experimental opening displacements along the whole crack height can be observed from the figure, which further demonstrates the reliability of the numerical model.

The TSC of concrete is capable of describing the softening properties of the FPZ and is usually employed to model the nonlinear fracture behavior of concrete by using FE method. According to the results in present study, the exponential softening curve determined by uniaxial tensile tests (Reinhardt et al., 1986) is suitable for normal strength concrete, while the exponential softening curve associated with the compressive strength (Chen \& Su, 2013) is preferable for high strength concrete.

\section{Conclusions}

In this study, the characteristics of the fracture process zone (FPZ) in two types of concrete, normal strength concrete (NSC) and high strength concrete (HSC), were investigated by conducting three-point bending test and FE simulation. The following conclusions can be drawn:

1) Based on the strain field measured by electronic speckle pattern interferometry (ESPI) technique, the development of the FPZ was qualitatively evaluated. The approximate extent of the FPZ could be defined as the damage zone where the tensile strain was more than $0.25 \times 10^{-3}$. In crack evolution, the formation of the FPZ is mainly caused by the localization and extension of the micro cracks and develops relatively slowly before the peak load. While after the peak load, the FPZ extends quickly and is mostly attributed to the bridging effect. Fracture toughening mechanisms, such as the development of micro cracks, crack deflection and crack branching, were observed due to the random distribution of the aggregates in concrete. Despite of these, the main crack always propagates towards the loading point and the fully developed FPZ presented a narrow and long band shape.

2) The FPZ length increased during crack propagation and was about $37 \mathrm{~mm}$ at the peak load, 0.35 times ligament length. At the post-peak $33 \%$ of the peak load, the FPZ was fully developed and reached a maximum of approximately $90 \mathrm{~mm}$ with a crack extension length to ligament length ratio of about 0.86. After that, the length of the FPZ decreased almost linearly. The maximum width of the FPZ is about 2.7 times the maximum aggregate size in present result.

3) Based on the cohesive crack model, the fracture behavior of three-point bending beam was numerical simulated by introducing three different softening functions. By comparing the numerical results with the experimental results, it could be found that the softening characteristic of the FPZ has little influence on the fracture response of concrete beams before the peak load due to the FPZ develops relatively slowly in the pre-peak stage. In this study, the exponential softening function obtained by uniaxial tensile tests gave the best predication of the test results for NSC, while the exponential softening function determined by inverse method and related to the compressive strength was appropriate to characteristic the softening relationship of HSC.

\section{Funding}

The work was supported by the National Natural Science Foundation of China (Grant No. 51768011, 51408144).

\section{Disclosure statement}

The authors declare that they have no known competing financial interests or personal relationships that could have appeared to influence the work reported in this paper. 


\section{References}

Arnautov, A. K., Bikovens, O., Gribniak, V., Nasibullins, A., Blumbergs, I., \& Hauka, M. (2016). Investigation on fracture of epoxy-filled composites by acoustic emission. Journal of Civil Engineering and Management, 22(5), 683-689.

https://doi.org/10.3846/13923730.2016.1157094

Bazant, Z. P., \& Cedolin, L. (1979). Blunt crack band propagation in finite element analysis. Journal of the Engineering Mechanics Division, 105, 297-315.

Bhowmik, S., \& Ray, S. (2019). An experimental approach for characterization of fracture process zone in concrete. Engineering Fracture Mechanics, 211, 401-419.

https://doi.org/10.1016/j.engfracmech.2019.02.026

British Standards Institution. (2007). BS EN 197-1:2000 CementPart 1: Composition, specifications and conformity criteria for common cements.

Cendón, D. A., Gálvez, J. C., Elices, M., \& Planas, J. (2000). Modelling the fracture of concrete under mixed loading. International Journal of Fracture, 103(3), 293-310. https://doi.org/10.1023/A:1007687025575

Chen, H. H., \& Su, R. K. L. (2011). Experimental study on fracture behavior of pre-notched mortar beams using ESPI technique. In Z. Bojkovic, J. Kacprzyk, N. Mastorakis, V. Mladenov, R. Revetria, L. A. Zadeh, \& A. Zemliak (Eds.), Recent researches in hydrology, geology and continuum mechanics (pp. 32-37). WSEAS Press.

Chen, H. H., \& Su, R. K. L. (2013). Tension softening curves of plain concrete. Construction and Building Materials, 44, 440451. https://doi.org/10.1016/j.conbuildmat.2013.03.040

Chen, H. H. N., Su, R. K. L., Fok, S. L., \& Zhang, H. G. (2017). Fracture behavior of nuclear graphite under three-point bending tests. Engineering Fracture Mechanics, 186, 143-157. https://doi.org/10.1016/j.engfracmech.2017.09.030

Cornelissen, H. A. W., Hordijk, D. A., \& Reinhardt, H. W. (1986). Experimental determination of crack softening characteristics of normalweight and lightweight concrete. HERON, 31(2), 45-56.

Dantec-Ettemeyer. (2001). ISTRA for Windows (Version 3.3.12).

Daoud, A., Maurel, O., \& Laborderie, C. (2013). 2D mesoscopic modelling of bar-concrete bond. Engineering Structures, 49, 696-706. https://doi.org/10.1016/j.engstruct.2012.11.018

Denarie, E., Saouma, V. E., Iocco, A., \& Varelas, D. (2001). Concrete fracture process zone characterization with fiber optics. Journal of Engineering Mechanics, 127(5), 494-502. https://doi.org/10.1061/(ASCE)0733-9399(2001)127:5(494)

Dong, W., Wu, Z., Zhou, X., Wang, N., \& Kastiukas, G. (2017). An experimental study on crack propagation at rock-concrete interface using digital image correlation technique. Engineering Fracture Mechanics, 171, 50-63. https://doi.org/10.1016/j.engfracmech.2016.12.003

Elices, M., Guinea, G. V., Gomez, J., \& Planas, J. (2002). The cohesive zone model: advantages, limitations and challenges. Engineering Fracture Mechanics, 69(2), 137-163. https://doi.org/10.1016/S0013-7944(01)00083-2

Gribniak, V., Rimkus, A., Torres, L., \& Jakstaite, R. (2017). Deformation analysis of reinforced concrete ties: Representative geometry. Structural Concrete, 18(4), 634-647. https://doi.org/10.1002/suco.201600105

Guo, Z. K., Kobayashi, A. S., \& Hawkins, N. M. (1993). Further studies on fracture process zone for Mode-I concrete fracture. Engineering Fracture Mechanics, 46(6), 1041-1049. https://doi.org/10.1016/0013-7944(93)90155-L
Hadjab-Souag, S., Thimus, J. F., \& Chabaat, M. (2007a). Detecting the fracture process zone in concrete using scanning electron microscopy and numerical modelling using the nonlocal isotropic damage model. Canadian Journal of Civil Engineering, 34(4), 496-504. https://doi.org/10.1139/106-132

Hadjab-Souag, S., Chabaat, M., \& Thimus, J. F. (2007b). Use of scanning electron microscope and the non-local isotropic damage model to investigate fracture process zone in notched concrete beams. Experimental Mechanics, 47(4), 473-484. https://doi.org/10.1007/s11340-006-9001-0

Haggerty, M., Lin, Q., \& Labuz, J. F. (2010). Observing deformation and fracture of rock with speckle patterns. Rock Mechanics and Rock Engineering, 43(4), 417-426. https://doi.org/10.1007/s00603-009-0055-Z

Hamad, W. I., Owen, J. S., \& Hussein, M. F. M. (2013). An efficient approach of modelling the flexural cracking behaviour of un-notched plain concrete prisms subject to monotonic and cyclic loading. Engineering Structures, 51, 36-50. https://doi.org/10.1016/j.engstruct.2013.01.007

Hillerborg, A., Modéer, M., \& Petersson, P. E. (1976). Analysis of crack formation and crack growth in concrete by means of fracture mechanics and finite elements. Cement and Concrete Research, 6(6), 773-781.

https://doi.org/10.1016/0008-8846(76)90007-7

$\mathrm{Hu}, \mathrm{X}$. Z. (2002). An asymptotic approach to size effect on fracture toughness and fracture energy of composites. Engineering Fracture Mechanics, 69(5), 555-564. https://doi.org/10.1016/S0013-7944(01)00102-3

$\mathrm{Hu}, \mathrm{X}$. Z., \& Duan, K. (2004). Influence of fracture process zone height on fracture energy of concrete. Cement and Concrete Research, 34(8), 1321-1330. https://doi.org/10.1016/j.cemconres.2003.12.027

Huntley, J. M., \& Saldner, H. (1993). Temporal phase-unwrapping algorithm for automated interferogram analysis. Applied Optics, 32(17), 3047-3052. https://doi.org/10.1364/AO.32.003047

Jakubovskis, R., Kupliauskas, R., Rimkus, A., \& Gribniak, V. (2018). Application of FE approach to deformation analysis of RC elements under direct tension. Structural Engineering and Mechanics, 68(3), 345-358.

https://doi.org/10.12989/sem.2018.68.3.345

Kanomata, T., Suzuki, T., Kaneko, T., Yasui, H., Miura, S., \& Nakagawa, Y. (2012). Size independent fracture energy of concrete. Construction \& Building Materials, 26(1), 357-361. https://doi.org/10.1016/j.conbuildmat.2011.06.034

Li, X., \& Marasteanu, M. (2010). The fracture process zone in asphalt mixture at low temperature. Engineering Fracture Mechanics, 77(7), 1175-1190.

https://doi.org/10.1016/j.engfracmech.2010.02.018

Pan, B., Qian, K., Xie, H., \& Asundi, A. (2009). Topical review: Two-dimensional digital image correlation for in-plane displacement and strain measurement: a review. Measurement Science \& Technology, 20(6), 062001. https://doi.org/10.1088/0957-0233/20/6/062001

Reinhardt, H. W., Cornelissen, H. A. W., \& Hordijk, D. A. (1986). Tensile tests and failure analysis of concrete. Journal of Structural Engineering, 112(11), 2462-2477.

https://doi.org/10.1061/(ASCE)0733-9445(1986)112:11(2462)

RILEM. (1985). TC 50-FMC fracture mechanics of concrete, determination of the fracture energy of mortar and concrete by means of three-point bend tests on notched beams. Materials and Structures, 18(4), 287-290.

https://doi.org/10.1007/BF02472918 
RILEM. (1990). TC 89-FMT fracture mechanics of concrete, determination of the fracture parameters (KIcs and CTODc) of plain concrete using three-point bend tests. Materials and Structures, 23(6), 457-460. https://doi.org/10.1007/BF02472029

Shah, S. P., Swartz, S. E., \& Ouyang, C. (1995). Fracture mechanics of concrete: Applications of fracture mechanics to concrete, rock and other quasi-brittle materials. New York: John Wiley \& Sons, Inc.

Siebert, T., Schubach, H. R., \& Splitthof, K. (2011). Recent developments and applications for optical full field strain measurement using ESPI and DIC. In Fourth International Seminar on Modern Cutting and Measurement Engineering. https://doi.org/10.1117/12.891864

Skarżyński, Ł., Syroka, E., \& Tejchman, J. (2011). Measurements and calculations of the width of the fracture process zones on the surface of notched concrete beams. Strain, 47(S1), 319332. https://doi.org/10.1111/j.1475-1305.2008.00605.x

Skarżyński, Ł., \& Tejchman, J. (2010). Calculations of fracture process zones on meso-scale in notched concrete beams subjected to three-point bending. European Journal of Mechanics, 29(4), 746-760.

https://doi.org/10.1016/j.euromechsol.2010.02.008

Sousa, J. L. A. O., \& Gettu, R. (2006). Determining the tensile stress-crack opening curve of concrete by inverse analysis. Journal of Engineering Mechanics, 132(2), 141-148. https://doi.org/10.1061/(ASCE)0733-9399(2006)132:2(141)

Su, R. K. L., Chen, H. H., Fok, S. L., Li, H., Singh, G., Sun, L., \& Shi, L. (2013). Determination of the tension softening curve of nuclear graphites using the incremental displacement collocation method. Carbon, 57, 65-78. https://doi.org/10.1016/j.carbon.2013.01.033

Su, R. K. L., Chen, H. H. N., \& Kwan, A. K. H. (2012). Incremental displacement collocation method for the evaluation of tension softening curve of mortar. Engineering Fracture Mechanics, 88, 49-62.

https://doi.org/10.1016/j.engfracmech.2012.04.005
Sze, K. Y., Fan, H., \& Chow, C. L. (1995). Elimination of spurious pressure and kinematic modes in biquadratic 9-node plane element. International Journal for Numerical Methods in Engineering, 38(23), 3911-3932.

https://doi.org/10.1002/nme.1620382302

Tang, Y. X., \& Chen, H. N. (2018). Simulation of crack propagation in concrete based on extended finite element method. Key Engineering Materials, 783, 165-169.

https://doi.org/10.4028/www.scientific.net/KEM.783.165

Wittmann, F. H., Rokugo, K., Brühwiler, E., Mihashi, H., \& Simonin, P. (1988). Fracture energy and strain softening of concrete as determined by means of compact tension specimens. Materials and Structures, 21(1), 21-32. https://doi.org/10.1007/BF02472525

Wu, Z. M., Rong, H., Zheng, J. J., Xu, F., \& Dong, W. (2011). An experimental investigation on the FPZ properties in concrete using digital image correlation technique. Engineering Fracture Mechanics, 78, 2978-2990. https://doi.org/10.1016/j.engfracmech.2011.08.016

Yuan, Q., Junrui, C., Weihua, D., Faning, D., Man, L., \& Zengguang, X. (2015). A quasi real-time approach to investigating the damage and fracture process in plain concrete by X-Ray tomography. Journal of Civil Engineering and Management, 22(6), 792-799. https://doi.org/10.3846/13923730.2014.914089

Zhang, C., Yang, X., \& Gao, H. (2018). Air-void-affected zone in concrete beam under four-point bending fracture. Journal of Civil Engineering and Management, 24(2), 130-137. https://doi.org/10.3846/jcem.2018.456 